\title{
An unusual case of infective endocarditis: annulus vegetation
}

\author{
Zafer Isilak, ${ }^{1}$ Onur Sinan Deveci, ${ }^{1}$ Murat Yalçın, ${ }^{1}$ Mehmet Incedayi ${ }^{2}$
}

${ }^{1}$ GATA Haydarpasa Teaching Hospital, Department of Cardiology, Istanbul, Turkey ${ }^{2}$ GATA Haydarpasa Teaching Hospital, Department of Radiology, Istanbul, Turkey

\section{Correspondence to}

Dr Mehmet Incedayi, m_incedayi@yahoo.com
To cite: Isilak Z, Deveci OS, Yalçın $\mathrm{M}$, et al. BMJ Case Reports Published Online First: [Please include Day Month Year] doi:10.1136/ bcr-2012-008089

\section{DESCRIPTION}

A 24-year-old man without any known cardiac disease was admitted to our hospital because of fever and general fatigue. On physical examination, his temperature was $39^{\circ}$ and cardiovascular examination revealed a $3 / 6$ holosystolic murmur in the left fourth intercostal space radiating to the axilla.

Two-dimensional and three-dimensional transthoracic echocardiography (TTE) revealed a mean left ventricular ejection fraction of $65 \%$, Left heart chambers were in normal size. TTE detected a floppy mass arising from the anterior leaflet of the mitral valve and moderate mitral regurgitation at apical four-chamber and parasternal long-axis windows (figures $1 \mathrm{~A}, \mathrm{~B}, \mathrm{D}$ and $2 \mathrm{~A}, \mathrm{~B}$ ). A subsequent real-time three-dimensional transesophageal echocardiography (3D-RT-TEE) was also conducted for precise anatomic definition. Surprisingly,
3D-RT-TEE revealed a $25 \times 27 \mathrm{~mm}$ floppy vegetation on the posterior annulus of the mitral valve with moderate-to-severe mitral regurgitation (figures 1D, 2C,D). The patient was diagnosed as infective endocarditis. Treatment with intravenous amipisilin plus gentamisin was initially started. His serial blood culture results were persistently negative. On day 7, as the patient developed dyspnoea suggestive of heart failure, therefore, the patient was referred to cardiac surgery, after the medical therapy has been revised to intravenous vancomycin plus gentamisin. The vegetation was successfully removed with surgery, and after 6 weeks of antibiotic therapy, the patient was discharged with total cure (figure 3 ).

In this case, real-time 3D echocardiography helped the cardiologist understand the morphological characteristics and precise localisation and attachment point of the vegetation.

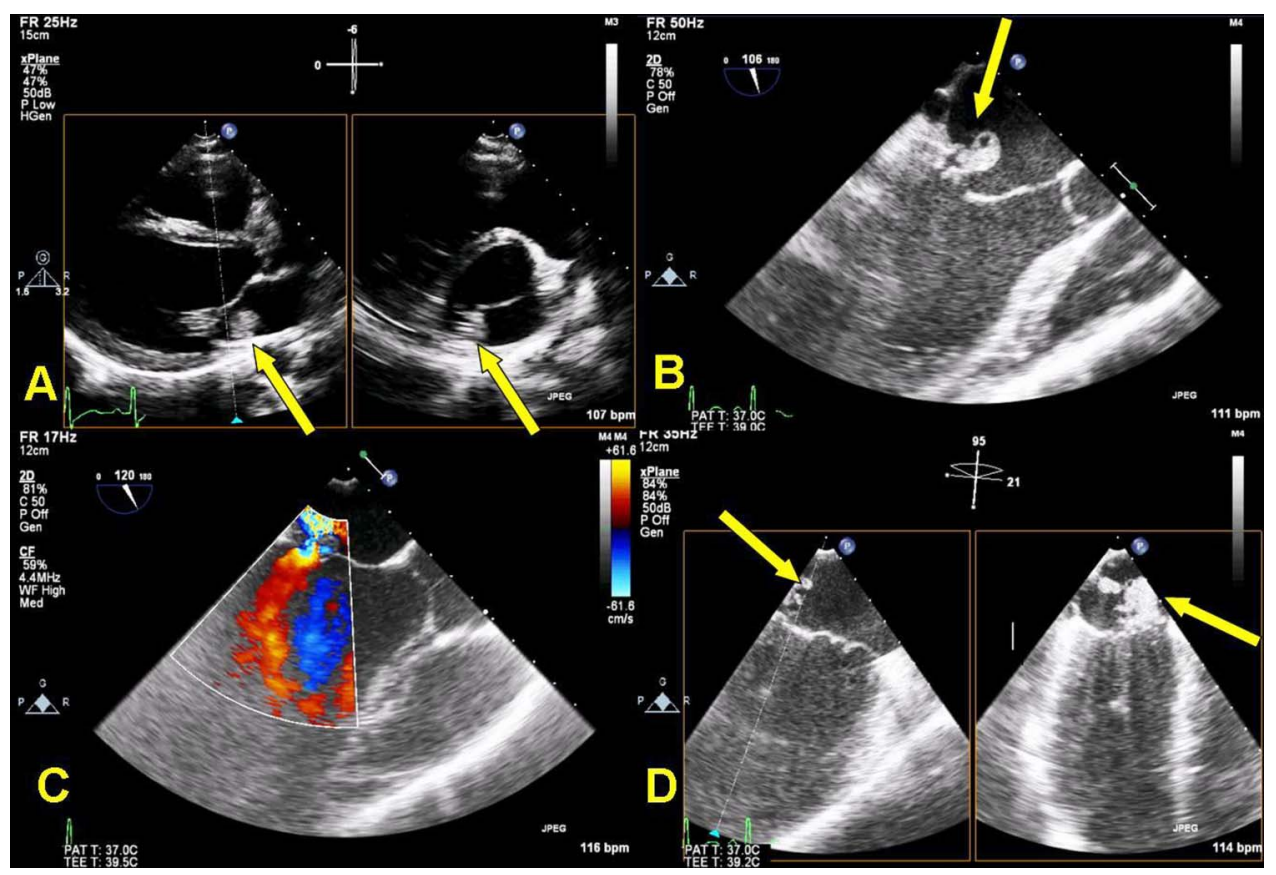

Figure 1 (A) parasternal long-axis window of two-dimensional and three-dimensional transthoracic echocardiography (TTE) demonstrates a floppy vegetation. (B) Three-dimensional transesophageal echocardiography (TEE) image from $100^{\circ}$ midesophageal level revealed the vegetation. (C) TEE image from $120^{\circ}$ midesophageal level showed vegetation and moderate-to-severe mitral regurgitation by colour Doppler echocardiography. (D) TEE image from X-plain $120^{\circ}$ midesophageal level showed vegetation. 


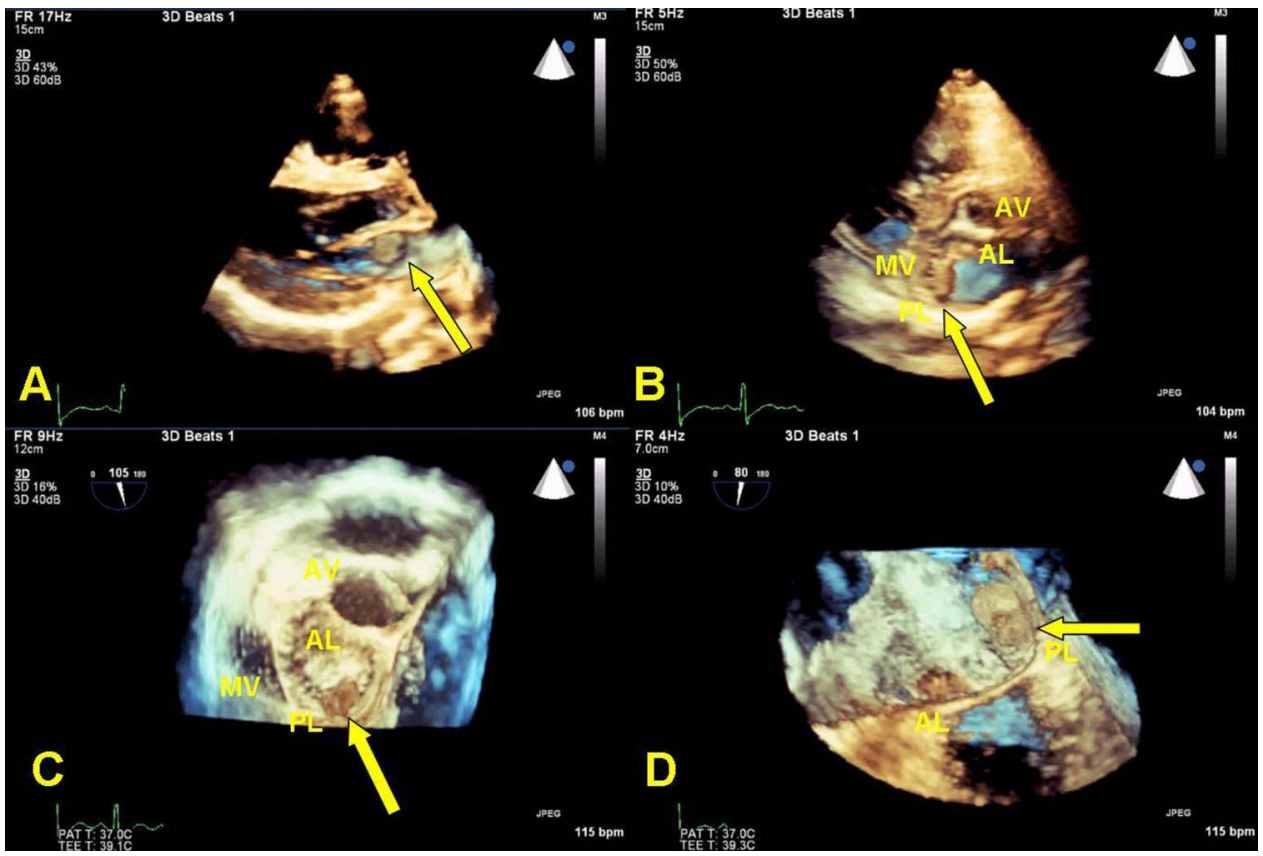

Figure 2 (A) Real-time three-dimensional transesophageal echocardiography (3D-RT-TEE) with mitral valve vegetation (arrow). (B) 3D-RT TTE from left atrial perspective with mitral valve vegetation (arrow) (C and D) 3D-RT-TEE from left atrial perspective with vegetation $(2.5 \times 2.7 \mathrm{~cm})$ involving posterior annulus of the mitral valve (arrow).

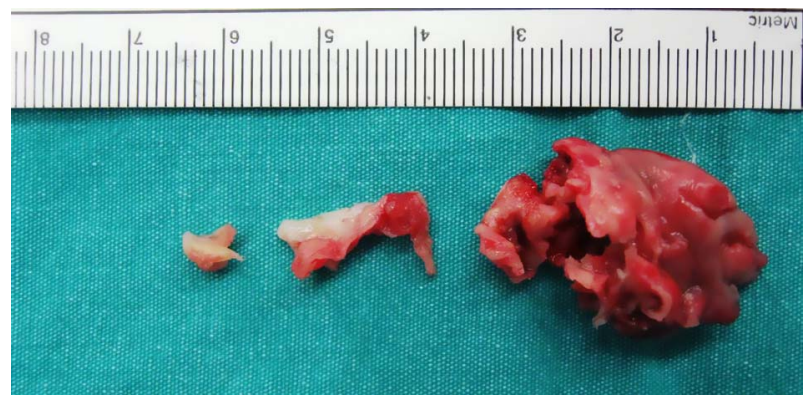

Competing interests None.

Patient consent Obtained.

Provenance and peer review Not commissioned; externally peer reviewed.

Figure 3 Image of the vegetation after surgical excision.

Learning points

- Vegetations due to infective endocarditis are usually seen in the leaflets of the heart valves; involvement of the annular regions is infrequent.

- In this case, real-time three-dimensional echocardiography helped the cardiologist understand the morphological characteristics and the precise localisation and attachment point of the vegetation.

Copyright 2013 BMJ Publishing Group. All rights reserved. For permission to reuse any of this content visit http://group.bmj.com/group/rights-licensing/permissions.

BMJ Case Report Fellows may re-use this article for personal use and teaching without any further permission.

Become a Fellow of BMJ Case Reports today and you can:

- Submit as many cases as you like

- Enjoy fast sympathetic peer review and rapid publication of accepted articles

- Access all the published articles

- Re-use any of the published material for personal use and teaching without further permission

For information on Institutional Fellowships contact consortiasales@bmjgroup.com

Visit casereports.bmj.com for more articles like this and to become a Fellow 